\title{
The Evolution of Macro Models at the Federal Reserve Board
}

\author{
Flint Brayton, Andrew Levin, Ralph Tryon, and John C. Williams* \\ Federal Reserve Board \\ Washington, D.C. 20551 \\ Revised: February 7, 1997
}

\footnotetext{
*This paper was prepared for the Carnegie-Rochester Conference on Public Policy, November 22-23, 1996. The authors gratefully acknowledge the comments of Robert King and Ben McCallum and participants at the conference. The macroeconomic models at the Federal Reserve Board described in this paper represent the work of many individuals at the Fed. Brayton and Williams participated in the project to build the FRB/US model, along with other members of the Macroeconomics and Quantitative Studies section in the Division of Research and Statistics. They would like to acknowledge the valuable assistance of Steve Sumner in preparing this paper. The FRB/MCM was developed in the Trade and Financial Studies section of the Division of International Finance. Levin and Tryon acknowledge valuable discussions with David Bowman, Chris Erceg, Dale Henderson, and John Rogers, and the excellent research assistance of Asim Husain and Jon Otting. Views presented are those of the authors and do not necessarily represent those of the Federal Reserve Board.
} 


\section{Introduction}

Large-scale macroeconometric models have been used for forecasting and quantitative policy and macroeconomic analysis at the Federal Reserve Board for the past 30 years. ${ }^{1}$ Model design and development efforts at the Fed have been divided into two complementary research programs. One project, undertaken in the Division of Research and Statistics, focuses on the U.S. economy, and the other, residing in the Division of International Finance, is oriented toward the global economy. For some applications, the macro models maintained by the two divisions are combined to form a single world model.

The first-generation Fed models-MPS and MCM — were developed in the 1960's and 1970's and based on the then-reigning IS/LM/Phillips curve paradigm. During the 1970's and 1980 's, the theoretical underpinnings of models of this type were seriously challenged. These criticisms, as well as improvements in econometric methodology and computational capabilities, led to a basic redesign of the Fed macro models in the 1990's. These secondgeneration models represent a significant improvement over their predecessors in the treatment of expectations, intertemporal budget constraints, and household and firm decisionmaking, while at the same time holding to a high standard of goodness of fit.

This paper describes the evolution of macro models at the Fed, with an emphasis on the structure and properties of the second-generation models currently in use. The next section summarizes the history of the initial pair of models used at the Fed—MPS and MCM—and section 3 presents the new ones, focusing on the combined FRB/WORLD model. Section 4 describes the system properties of this new model, and the last section provides examples of how it may be used for policy analysis. Conclusions then follow.

\section{The First Generation of Macro Models at the Fed}

The initial phase of macro modeling at the Federal Reserve Board began in the late 1960's with the construction of the MPS model of the U.S. economy and continued in the 1970's with the building of the Multi-Country Model (MCM). The decisions to develop these models were made at a time when interest in large-scale macroeconomic models was widespread—in the academic community and elsewhere—and advances in computer tech-

\footnotetext{
${ }^{1}$ Reifschneider, Stockton, and Wilcox (1997) discuss the uses of these and other economic models at the Federal Reserve Board.
} 
nology were making the use of such models feasible, as demonstrated by the Brookings Model, work on which had started in the early 1960's. This favorable climate for model building fostered projects to develop other large-scale models of the U.S. economy, including the MPS model. Soon thereafter, modeling efforts expanded from the development of isolated national models to ones having a more international perspective. The MCM was one of the first major efforts in this direction.

\subsection{6-1975: Focus on the U.S. Economy}

Work on the MPS model began in 1966 as a joint effort among a group of academic economists and staff members of the Division of Research and Statistics at the Federal Reserve Board. Leading the project were Franco Modigliani of MIT, Albert Ando of the University of Pennsylvania, and Frank de Leeuw of the Fed. ${ }^{2}$ The model entered into operational use by Board staff in 1970 for forecasting and policy analysis. The initial operational version of MPS contained about 60 behavioral equations, making it considerably smaller than the Brookings model, versions of which contained 200 or more behavioral equations.

Much of the basic structure of the first version of MPS was retained throughout its period of use at the Fed, which ended in 1995. In that structure, short-run dynamics followed the IS/LM paradigm, augmented with a Phillips curve specification of wage inflation and a markup equation for the price level. Underlying these dynamics were a long-run neoclassical growth model of production and factor demands and the life-cycle model of consumption. In this structure, the long-run level of output was determined by supply factors. Careful attention was paid to imposing homogeneity conditions, such as those needed to ensure the neutrality of money in the long run, and to including sectoral budget constraints. The role of expectations was recognized; however, in practice expectations were characterized as adaptive or implicitly subsumed in the lags of explanatory variables included in various equations.

Because MPS was designed for use in the analysis of stabilization policies, close attention was given to the inclusion of a wide range of monetary and fiscal policy "levers" and to the delineation of the mechanisms through which movements in policy instruments

\footnotetext{
${ }^{2}$ For descriptions of early versions of MPS, see Ando and Modigliani (1969), Rasche and Shapiro (1968), de Leeuw and Gramlich (1968, 1969), and Ando and Rasche (1971). The 1985 version is presented in Brayton and Mauskopf (1985). MPS is an abbreviation of MIT, University of Pennsylvania, and $\underline{\text { Social }}$ Science Research Council.
} 
affected the macro economy. The attention paid to fiscal policy reflected, in part, the optimistic view of the time that discretionary fiscal actions could be an important ingredient in countercyclical macro policies. With regard to monetary policy, the model contained three primary transmission channels: effects of the user cost of capital on investment, nonhuman wealth on consumption, and credit rationing on housing construction (de Leeuw and Gramlich, 1969). These channels all operated through interest rates and included equations linking long-term interest rates to short-term rates and the stock market to bond rates. Aside from their influence on short-term interest rates, monetary quantities had virtually no effects outside of the monetary sector itself. A monetary real balance effect operated through the influence of wealth on consumption, but its quantitative significance was minimal.

Up until the early 1970's, most modelers interpreted the inflation experience of the postwar period as supporting the presence of a long-run tradeoff between inflation and unemployment, and in this respect the properties of the first operational version of MPS were no different than those of other large-scale models (de Menil and Enzler, 1972). The increases in inflation of the late 1960's and very early 1970's, however, suggested that the long-run Phillips curve was vertical, and this was incorporated into the model's structure (Enzler and Pierce, 1974). The wage-price block in MPS remained little-changed for the next 20 years and came to be regarded as one of the more stable parts of the model (Ando and Brayton, 1995).

The first oil-price shock motivated additional work on the supply side of MPS. In an article written in early 1974, soon after the initial jump in world oil prices, Enzler and Pierce (1974) used the MPS model to provide a reasonably accurate assessment of the "stagflationary" consequences of a sustained increase in the relative price of energy. At the time, the model did not formally contain many of the linkages from oil prices to other macroeconomic variables needed to carry out the experiment, and Enzler and Pierce had to deal with omitted effects in ad hoc ways. Later, as an outgrowth of their work, the model's supply structure was revised to include energy as a factor of production and to permit differential effects of energy and food prices on the prices for components of final demand.

Another major shift in the economic climate in the early 1970's was the collapse of the Bretton-Woods system of fixed exchange rates, following on the exchange rate crises of the 1960 's. At the time, MPS had only a very rudimentary foreign trade sector in which exports 
were exogenous; moreover, the exchange rate did not appear in the model at all. In response to the floating of exchange rates and the growing importance of trade flows, the trade sector was significantly enlarged. A set of portfolio-balance equations for international financial capital stocks were included to endogenize the exchange rate. Still, MPS remained a singlecountry model with just a few equations representing foreign economic developments.

\subsection{5-1980: An International Focus}

The experience of the first oil shock and the floating of exchange rates, along with other events, combined to raise interest in global macroeconomic modeling. The increasing openness of the U.S. economy and growth in other industrial countries increased the importance of foreign economic developments and trade on the domestic economy. The OPEC oil shock of 1974 underscored the dramatic effects that external supply shocks could have on the U.S. economy.

Against this background, the Division of International Finance at the Federal Reserve Board began in 1975 to develop a multi-country econometric model that could be used to model the external sector of the U.S. economy more completely than existing models and to provide an empirical framework for modeling interactions among the major industrial countries. This project was one of the first efforts to build a multi-country econometric model, following on the pioneering work by Lawrence Klein on Project LINK.

The first version of the Multi-Country Model (MCM) modeled the economies of Canada, Germany, Japan, the U.K., the U.S., and a rest-of-world (ROW) sector. In total, the MCM contained over 200 behavioral equations. Like the MPS model, the basic framework for the MCM model combined the short-run dynamics of the IS/LM/Phillips curve paradigm and implicit expectations with a long-run neoclassical growth model.

The MCM built upon extensive empirical research in two areas of international economics. One was the modeling of international capital flows, which had received a great deal of attention in the fixed exchange rate regime of the 1960's, and the other the modeling of bilateral trade flows. In its original incarnation, the MCM used bilateral equations to model goods trade among the individual countries, and multilateral equations to explain gross inflows and outflows of both direct and portfolio claims and liabilities. Reaction functions were used to describe official exchange market interventions, and the nominal exchange rate was determined implicitly, as the price that cleared the balance of payments. 
The domestic financial sector of each country was modeled in keeping with this portfoliobalance approach to the balance of payments. The private banking sector was modeled explicitly, with the demand for the monetary base derived from banks' desired reserves. The authorities controlled the monetary base, and the short-term interest rate cleared the money market. The demand for bonds was also modeled explicitly, and the long-term interest rate cleared the bond market rather than being determined in an explicit term-structure relation.

Guy Stevens led the effort to develop the original MCM, which was completed and brought into regular use at the Board in 1979. Stevens et al. (1984) describes the first version of the MCM in detail. Its primary use was to simulate the effects of alternative policy scenarios and external shocks. The MCM was not used directly for forecasting, although simulations of alternative scenarios provided an input into forecasts of foreign activity and the U.S. external sector.

\subsection{0-1990: Incremental Changes}

After their initial development, changes to MPS and MCM came about in response to economic events, changes in institutional and regulatory structure, and, to a lesser extent, developments on the academic front. For the most part, revisions were incremental through the 1980 's and very early 1990's. In the current decade, resources were redirected to the design and construction of new models that incorporated more fully innovations in macroeconomic theory and econometrics.

On the domestic side, financial innovation and deregulation resulted in changes in credit and money markets that necessitated significant revisions to the MPS model. Almost onethird of the behavioral equations in the first version of MPS were in the housing and mortgage sectors. At the time, the rationing of mortgage credit that accompanied a rise in market interest rates was a key mechanism through which monetary policy actions influenced the economy. In the late 1970's and early 1980's, the factors responsible for the rationing of mortgage funds_-legislated ceilings on interest rates paid on deposits and the lack of integration between mortgage markets and other capital markets-disappeared, leading to a dramatic simplification of the financial block of the model. Because mortgage quantities were no longer needed in the equations for residential construction, the detailed mortgage sector was replaced with a single equation in which the mortgage rate was related to other market interest rates. This change, in turn, eliminated the need to have a detailed model of 
deposit flows and interest rates at thrift institutions.

Financial innovation and deregulation, and associated shifts over time in the emphasis placed by policymakers on various shorter-term monetary instruments and targets, led to further revisions to the monetary sector of MPS. In the initial version of the model, the reserves market received considerable attention, and early presentations of the model's system properties were usually based on the assumption that nonborrowed reserves was the exogenous instrument of policy. As the 1970's progressed, however, policy simulations were based most frequently on the assumption that M1 was exogenous, making the reserves equations largely superfluous. Later, the instability of M1 demand equations led to a greater emphasis on M2, which was mirrored in an expansion of the monetary sector to include interest rate and quantity equations for components of M2. More recently, attention to the model's monetary sector diminished as instability of the demand equations for M2 caused short-run characterizations of policy to be stated in terms of the federal funds rate.

On the international side, several trends in academic economics contributed to an important change in the modeling of the international accounts in the MCM. In its original version, the balance of payments was modeled using a structural, portfolio-balance framework. But, the assumptions required to specify and estimate equations for capital flows led to dissatisfaction with this approach. The overshooting model of Dornbusch (1976) provided an attractive alternative that offered an open-economy model of exchange rate determination in a risk-neutral framework. These and other factors led to the use of a modified interest parity relationship in the MCM to determine exchange rates, in place of the capital flow equations. Similar considerations led to the elimination of the banking sector from the country models. Instead, the authorities were assumed to control either the money stock or the short-term interest rate.

The second oil shock gave rise to the explicit inclusion of oil in the MCM, a non-trivial extension because the bilateral trade equations used in the model at the time explained total goods trade. The model was also reestimated, and many equations respecified, using some of the error-correction specifications and methods of residual analysis suggested by David Hendry and other LSE econometricians. Edison, Marquez, and Tryon (1989) describe these and other changes to the MCM.

The final restructuring and reestimation of MCM came in 1991-1992 when it was extended to 12 regions (individual models for the G-7 and Mexico, plus aggregate blocks for 
other OECD countries, the newly industrialized economies, OPEC, and ROW). The other significant modification made at this time was replacing the bilateral trade structure with a multilateral one. This change greatly simplified the model's data requirements and the analysis of simulation results for a given country.

\section{FRB Policy Models Today}

Among academics, interest in large-scale macroeconomic models started to diminish in the 1970 's, and subsequently a large gulf emerged between applied macroeconomics as practiced by academics and that contained in large-scale models. The basic underpinnings of the traditional IS/LM/Phillips curve model were challenged on a number of fronts, including identification, treatment of expectations, and econometric methodology. This led to a fundamental overhaul of both the MPS and MCM models, culminating in a set of replacement models-FRB/US, FRB/MCM, and the combined FRB/WORLD. From the beginning, the new models were designed to incorporate explicit specifications of expectation formation and intertemporal decision making. In this way, the criticisms of the first-generation models were at least partially addressed.

\subsection{Motivations for Fundamental Changes}

Some academic reviews of the macroeconomic models of the 1970s were, if nothing else, blunt: Lucas and Sargent (1978) described the "spectacular failure" of Keynesian macro models and Sims (1980) characterized the identification restrictions in these models as "incredible." Underlying these and other criticisms was the general theme that economic theory had to be relied on more heavily for guidance in specifying structural equations. In particular, applied macroeconomic analysis needed to give more attention to the role of expectations in economic decisions.

Several specific developments in applied macroeconomics that grew out of these concerns were important in the decision to build a new set of macro models at the Fed, rather than to continue the approach of incremental revisions. One was the burgeoning use of the rational expectations assumption in applied research subsequent to Lucas's (1976) critique that policy analysis could not be conducted using models that failed to identify fundamental structural parameters. Another was the development of models of dynamic optimization 
and their use in many macroeconomic applications.

A related issue concerned methods by which a model's system properties could be evaluated. The vast literature on atheortic VARs initiated by Sims (1980) provided useful benchmarks against which structural models could be gauged. On the econometric front, the work of Engle and Granger (1987) and others provided a framework for the estimation and testing of long-run relationships.

The decision to construct new macro models was also motivated by a desire to address issues that could not be analyzed adequately given the treatment of expectations in the existing models. One set of such issues concerned effects of expected shifts in fiscal policy on the level of long-term interest rates. Could a long-term fiscal consolidation induce a reduction of long-term interest rates large enough to offset its direct negative effects on aggregate demand? The first attempt to address this question with the MPS model was undertaken in the early 1980's by Jared Enzler and Eileen Mauskopf. Simulations were conducted with a version of the model in which the standard term structure and stock market equations, which contained adaptive expectations, were replaced with alternatives incorporating rational expectations.

A second issue of interest to policymakers was the cost, in terms of foregone output, of reducing the rate of inflation. In the MPS and MCM models, the (nearly) linear structure and assumption of adaptive expectations made the standard measure of this cost- the output sacrifice ratio-independent of such factors as the speed with which a disinflation took place and the degree to which the public understood or believed in a policy to reduce inflation. Although these models provided an estimate of the sacrifice ratio, they were not useful in analyzing the determinants of the costs of disinflation and how policy could be designed to minimize these costs.

Even with these stimulants for the development of new macro models featuring rational expectations, their construction did not take place overnight. The technical requirements for estimating and simulating large-scale models with rational expectations are substantial. And the standard rational expectations assumption is not necessarily the superior choice, given costs of acquiring and processing information. 


\subsection{0-1996: The Development of New Macro Models}

Projects to develop a new pair of macroeconomic models were initiated in the early 1990's. Work on the successor to MPS started in 1991, while development of a new version of the MCM began in 1993. FRB/US and FRB/MCM officially replaced the earlier generation of models in 1996, and a version which links the foreign country models of FRB/MCM with FRB/US, called FRB/WORLD, is now the main policy model at the Board. FRB/US is also used for short-run forecasting. FRB/WORLD contains over 250 behavioral equations, of which 40 describe the U.S. economy and the rest describe the 11 other countries and regions. The large size and degree of disaggregation in the models is due, in part, to the requirement that they be able to execute a wide range of types of simulations and provide estimates of outcomes for a large set of variables of interest. Equations are estimated with single-equation techniques; model size precludes full-system estimation at this time, but simultaneous estimation of blocks of equations is planned.

In terms of basic structure, the new models share several features with the old. In the short run prices are sticky and output is determined by aggregate demand. In the long run prices adjust fully and the equilibrium is determined by supply factors. The differences lie primarily in the specification of expectations and the process of dynamic adjustment to the long-run equilibrium.

The three basic building blocks of FRB/WORLD are equilibrium conditions, expectation formation, and dynamic adjustments. Equilibrium conditions describe the relationships between macroeconomic variables when adjustment dynamics are fully worked out. Among the fundamentals that shape the long-run equilibrium allocation of resources in each country/region are three-factor (labor, capital, and energy) Cobb-Douglas production functions which determine aggregate supply and equilibrium factor demands.

FRB/WORLD ascribes an important role to expectations. Anticipated values of future variables directly influence interest and exchange rates, various components of aggregate demand, and wages and prices. Recognizing that no single assumption regarding the formation of expectations is likely to be appropriate in all circumstances and that it may be useful to see how different specifications in this regard affect system properties, the new model has been designed to have the flexibility to be simulated under alternative assumptions about how expectations are formed. At present, two options (or combinations thereof) are available: backward-looking, or adaptive, expectations and model-consistent, or ratio- 
nal, expectations.

For the U.S. component of FRB/WORLD, adaptive expectations is implemented by assuming that all agents share a common small vector autoregression (VAR) model of the economy that includes past observations of inflation, interest rates, output, and long-run expectations of inflation and interest rates. Firms and households use this small model, augmented with additional equations for variables specific to a particular sector, to forecast future values of quantities of interest. In the other countries, adaptive expectations are represented by univariate processes.

VAR-based or adaptive expectations limit the information set that is assumed to be available. At the other extreme is the model-consistent, or rational, assumption in which expectations are generated using the predicted values from the model itself. Solutions under model-consistent expectations are implemented using a variant of the extended path method introduced by Fair and Taylor (1983). The future path of exogenous variables is assumed to be known in advance. Due to the computational costs associated with this method, a loglinearized version of the U.S. model has been created that can be solved efficiently using the AIM implementation (Anderson and Moore, 1985) of the Blanchard-Kahn solution method.

The focus on expectations formation in general, and rational expectations in particular, necessitated that even more attention be given to equilibrium properties than was the case in the first-generation models. For example, budget constraints on the present discounted value of fiscal and external deficits are necessary for rational expectations solutions to exist. Long-run fiscal solvency is maintained by an endogenous tax rate reaction function, which adjusts the income or sales tax rate when the ratio of nominal government debt to GDP deviates from a specified target. Similarly, changes in the ratio of net external debt to GDP lead to corresponding movements in the sovereign risk premium. Thus, through uncovered interest parity, a deterioration of the current account induces an increase in the domestic real interest rate and/or a depreciation of the real exchange rate. A reasonable degree of sovereign risk premium adjustment ensures that improved net exports of goods and non-factor services will outweigh the higher net factor payments resulting from the initial increase in external debt, and thereby prevents an explosive path for the current account and net external debt.

The final building block is dynamic adjustments. A clear distinction is made between 
the behavior of financial variables—bonds, equity, and the exchange rate-where adjustment to fundamentals is assumed to be instantaneous, and nonfinancial variables - such as demand components, prices, and wages—which adjust gradually. In the U.S. sector, decision rules based on a generalized model of adjustment costs are used for many key nonfinancial equations, and error correction specifications are used elsewhere. The non-U.S. sectors employ Taylor's (1980) staggered contracts model for wages, and error correction or partial adjustment specifications otherwise.

\subsection{The U.S. Sector}

Not surprisingly for a Fed macro model, considerable attention was given to depicting as realistically as possible the implications of U.S. monetary policy actions on the U.S. economy. A main concern in this regard was the specification of dynamics associated with real and nominal rigidities and the role of expectations in intertemporal decision making. For a more detailed description of FRB/US, see Brayton and Tinsley (1996).

A distinguishing feature of the U.S. sector is the use of a new model of generalized adjustment costs developed by Tinsley (1993). As is well known, the standard linearquadratic (LQ) model of adjustment costs frequently does a poor job in characterizing the dynamic behavior of macroeconomic variables. The generalized model of adjustment costs employed here, named PAC for "polynomial adjustment costs," permits richer dynamics within a theoretically-based framework that is parsimonious with regard to coefficients and contains testable restrictions. Because of its central role in the U.S. sector, as well as its generally successful application as gauged by the goodness of fit of equations and their performance on misspecification tests, we describe the derivation and implementation of PAC before presenting the structure of the sector more broadly.

Adjustment Dynamics. The adjustment dynamics of most major nonfinancial variables, including consumption, investment, hours and the price and wage levels, are based on the PAC approach. (In the following equations, all future-dated variables should be interpreted as expected values even when the expectations operator has been suppressed.) Several observationally-equivalent cost functions can be used to derive the PAC specification. One such cost function, $C_{t}$,

$$
C_{t}=\sum_{i=0}^{\infty} \beta^{i}\left[\left(y_{t+i}-y_{t+i}^{*}\right)^{2}+\sum_{k=1}^{m} b_{k}\left((1-L)^{k} y_{t+i}\right)^{2}\right]
$$


penalizes both deviations of a variable $y$ from its desired value $y^{*}$ —as determined by an equilibrium condition-and movements in the level and $m-1$ time derivatives of the variable $y . \beta(=.98)$ is a discount factor, and $b_{k}, k=1, \ldots, m$, are cost parameters. A special case of the cost function, popular in the applied macro literature, is that of quadratic adjustment costs on changes in the level of $y(m=1)$. (Inventory research frequently uses specifications that are similar to the case $m=2$.) As will be shown, the form of generalized adjustment costs in equation (1) leads to a closed-form decision rule that is well-suited for empirical work. ${ }^{3}$ We will use the terms equilibrium, target, and desired value interchangeably to describe $y^{*}$.

Minimization of costs yields the Euler equation,

$$
\left(y_{t}-y_{t}^{*}\right)+\sum_{k=1}^{m} b_{k}[(1-L)(1-\beta F)]^{k} y_{t}=0,
$$

where $L$ is the lag operator and $F\left(\equiv L^{-1}\right)$ is the lead operator. This expression can be written more compactly as

$$
A(\beta F) A(L) y_{t}-c y_{t}^{*}=0,
$$

where $A$ is a polynomial in the lag and lead operators of order $m$, e.g., $A(L)=1-$ $a_{1} L-\ldots-a_{m} L^{m}$ and $A(\beta F)=1-a_{1} \beta F-\ldots-a_{m} \beta^{m} F^{m}$, and $c=A(1) A(\beta)$ is a constant. The $m$ parameters in $A$ are transformations of the $m$ cost parameters in equation (1). Because the dynamic structure of $y_{t}$ is factored into separate lead and lag polynomials, multiplication of equation (3) by $A(\beta F)^{-1}$ yields, after simplification, the decision rule

$$
\Delta y_{t}=A(1)\left(y_{t-1}^{*}-y_{t-1}\right)+A^{*}(L) \Delta y_{t-1}+D(F) \Delta y_{t}^{* e} .
$$

According to this equation, $\Delta y$ responds to the lagged gap between the level of $y$ and its equilibrium value, to lagged values of $\Delta y$, and to future values of $\Delta y^{*}$, which here are explicitly indicated to be expected values. Note that the decision rule takes an error correction form augmented with terms associated with expected growth in the target.

The term $A^{*}(L) \Delta y_{t-1}$ represents the $m-1$ lags of the dependent variable that enter be-

\footnotetext{
${ }^{3}$ In contrast, the generalized model of adjustment costs analyzed by Hansen and Sargent (1980) does not have a closed-form analytic solution.
} 
cause of higher-order adjustment frictions that are absent in the standard LQ specification, ${ }^{4}$ while the expression $D(F) \Delta y_{t}^{* e} \equiv \sum_{i=0}^{\infty} d_{i} \Delta y_{t+i}^{* e}$ is an infinite forward sum which has a mean lead that increases with the magnitude of adjustment frictions. The forward weights, $d_{i}$, are nonlinear functions of $\beta$ and the parameters of the polynomial $A .^{5}$ The advantage of this approach is clear: The presence of multiple lags of the dependent variable provides a much better match to the dynamic behavior of major macroeconomic time series. At the same time, this framework imposes a testable set of nonlinear restrictions among the coefficients on the lag and lead terms.

Estimation of equation (4) is a three-step process. Coefficients in the construction of $y^{*}$ are estimated or imposed on the basis of theoretical priors in the first step. In the second, a forecasting model for $\Delta y^{*}$ is estimated, and the adjustment coefficients, $A(1)$ and $A^{*}(L)$, are estimated in the last step.

To model expectations, a VAR approach is used in which a "core" VAR for five macro variables - the federal funds rate, consumer price inflation, the output gap (the deviation between output and an estimate of potential), long-run inflation expectations (survey-based), and long-run interest rate expectations (forward rates) - is common to expectations across all sectors, and "auxiliary" VAR equations are added for sector-specific variables. Equations for sector-specific variables contain lags of both the core variables and of themselves, whereas the equations for the first three core variables contain only lags of the core variables themselves. Long-run inflation and interest rate expectations, which are included to anchor the VAR projections, are assumed to follow random walks (Kozicki, Reifschneider, and Tinsley, 1996; and Kozicki and Tinsley, 1996). The underlying principle of the VAR approach is that, at a minimum, agents understand the main features of the economy as represented by a a small-scale model, and use this information to form the necessary expectations.

The adjustment equation is linear in variables, and its nonlinear coefficient restrictions can be imposed with an iterative OLS procedure that, at each iteration, restricts the forward

\footnotetext{
${ }^{4} A^{*}(L)$ is implicitly defined by the identity $A(L)=A(1) L+\left[1-A^{*}(L) L\right](1-L)$.

${ }^{5}$ As shown in Tinsley (1993), $d_{i}=c \iota_{m}^{\prime}\left[I_{m}-G\right]^{-1} G^{i} \iota_{m}$, where $\iota_{m}$ is a $1 \times m$ vector with a one in the $m t h$ element and zeroes elsewhere, and $G$ is the $m \times m$ matrix
}

$$
G=\left[\begin{array}{cccc}
0 & & I_{m-1} & \\
-a_{m} \beta^{m} & -a_{m-1} \beta^{m-1} & \ldots & -a_{1} \beta
\end{array}\right] .
$$


weights to values determined by estimates of the adjustment coefficients from the prior iteration. Implementation of nonlinear least squares estimation is also straightforward. In most cases, the order of adjustment costs $(m)$ is determined empirically by testing to see how many lags of the dependent variable are significant, and then including all lags up through the last significant one.

For some nonfinancial variables in the U.S. model, the PAC framework is modified to take account of factors such as the presence of agents that are unable to optimize (e.g., liquidity-constrained consumers and firms) and particular institutional aspects of markets or features of data measurement. To illustrate how the adjustment-cost framework outlined above is applied and, in many cases, augmented, equations in three U.S. sectorsinventories, the wage-price block, and investment in producers' durable equipment—are presented in some detail. In the following, symbol definitions, which are given in table 1, generally use uppercase characters for levels (or rates) and lowercase characters for logarithms.

Inventories. The equation for the logarithm of the stock of manufacturing and trade inventories, $h$, closely follows the adjustment-cost framework described above. Because the inventory-output ratio is stationary, the equilibrium condition imposes a constant target inventory-output ratio,

$$
h_{t}^{*}=x_{b, t}
$$

Note that in this equation and the ones that follow, constant terms are suppressed.

The dynamic adjustment equation for inventories contains a highly significant errorcorrection term and three lags of inventory growth,

$$
\begin{aligned}
& \Delta h_{t}=0.150\left(h^{*}-h\right)_{t-1}+0.231 \Delta h_{t-1}+0.118 \Delta h_{t-2} \\
& +\quad \begin{array}{l}
0.122 \Delta h_{t-3} \\
\quad(1.6)
\end{array}
\end{aligned}
$$

$$
\text { span: 62q3-94q4 } \quad \mathrm{R}^{2}: \quad .42 \quad \text { SEE: } .0065
$$

The forward expectations term is written with the dating of expectations (t-1) and the 
weight sum (0.533) indicated explicitly. No t-statistic was calculated for the weight sum; this parameter is constrained in the adjustment model to be a function of $\beta$ and the coefficients on the error-correction term and the lags of the dependent variable, as is the profile of the forward weights, $f_{h, i}$. The mean lead of the forward terms in the product $A(L) A(B F)$, the lead/lag polynomial which multiplies the decision variable in equation (3), provides a compact measure of how far ahead agents look as well as how quickly a variable adjusts to its target level. Because the lead/lag polynomial is nearly symmetric, the mean response lag is similar to the mean expectations lead. For inventories, the mean lead is 2.6 quarters, indicating that the expectations horizon is short and adjustment is rapid.

Prices and Wages. The price-wage block contains two features not present for inventories: The targets include a stationary cyclical component, and variables appear in the dynamic equations that lie outside the PAC framework. The mixing of stationary and nonstationary variables in the equilibrium condition requires that the dividing line between the first and third estimation steps be modified. Rather than separating the estimation of coefficients on the basis of whether they are part of equilibrium condition or adjustment dynamics, in this case the split is made on the basis of whether they are associated with nonstationary or stationary variables. The price-wage system contains a single long-run condition among nonstationary variables_-based on a three-factor Cobb-Douglas production technology_in which the equilibrium price level is a constant markup over minimized cost,

$$
p_{g, t}^{*}=.98\left(w_{t}-\rho_{t}\right)+.02 p_{e, t}
$$

where $p_{g}$ is a price index for adjusted nonfarm business output, $w-\rho$ unit labor costs, and $p_{e}$ a price of crude energy. The estimated cointegrating relationship underlying equation (7) is renormalized to define the equilibrium wage,

$$
w_{t}^{*}=\rho_{t}+(1 / .98) p_{g, t}-(.02 / .98) p_{e, t} .
$$

In these equilibrium equations the price level is indeterminate, and, out of equilibrium, the price gap is simply the (scaled) negative of the wage gap,

$$
p_{g, t}^{*}-p_{g, t}=-(1 / .98)\left(w_{t}^{*}-w_{t}\right)
$$


Table 1: Definitions of Symbols

\begin{tabular}{|c|c|}
\hline Symbol & Definition \\
\hline CFLOW & Corporate after-tax cash flow \\
\hline$C C$ & Cost of capital \\
\hline$D$ & Dividends \\
\hline$D_{w p c}$ & Dummy variable for wage and price controls \\
\hline$\delta$ & Depreciation rate \\
\hline$f_{j, t+i}$ & Forward weight in equation $j$ for expectation of nonstationary variable \\
\hline$g_{j, t+i}$ & Forward weight in equation $j$ for expectation of stationary variable \\
\hline$H$ & Stock of manufacturing and trade inventories \\
\hline$K$ & Capital stock \\
\hline$P$ & Absorption price index (GDP + imports - gov't labor - inventories) \\
\hline$P_{b}$ & Price index for business output \\
\hline$P_{g}$ & Price index for nonfarm business output less housing + oil imports \\
\hline$P_{e}$ & Price index for crude energy \\
\hline$P_{f}$ & Relative price of imports \\
\hline$P_{i} / P$ & Relative price level \\
\hline$P_{o}$ & Price of $X_{o}$ \\
\hline$\pi^{e}$ & Expected inflation \\
\hline$\Pi$ & After-tax profits \\
\hline$R_{s}$ & Short-term interest rate \\
\hline$R_{L}$ & Corporate bond rate \\
\hline$\rho$ & Trend productivity \\
\hline$S I T A X$ & Weighted growth rate of employer social insurance taxes \\
\hline$T$ & Time trend \\
\hline TOT & Terms of trade \\
\hline$U$ & Unemployment rate \\
\hline$V$ & Tangible wealth \\
\hline$W$ & Compensation per hour \\
\hline$W_{\min }$ & Minimum wage (relative to lagged 4-quarter average of $W$ ) \\
\hline$\omega_{e}$ & Scaled ratio of $P_{e}$ to $P_{b}$ \\
\hline$X$ & GDP (actual or potential) \\
\hline$X_{b}$ & Business sector output \\
\hline$\Delta \bar{x}_{b}$ & Average rate of growth of $X_{b}$ \\
\hline$X_{g}$ & Nonfarm business output less housing plus oil imports \\
\hline$X_{o}$ & $\begin{array}{l}\text { Output of non-business sectors plus nonoil imports less } \\
\text { government labor and inventories }\end{array}$ \\
\hline$X_{s}$ & Domestic sales \\
\hline$Y$ & Household or disposable income \\
\hline$\tilde{y}$ & Output gap (actual - potential) \\
\hline$Z$ & Optimal capital-output ratio \\
\hline \multicolumn{2}{|c|}{$\begin{array}{l}\text { Notes: } \\
\text { 1. Lower case letters are used to denote logarithms. } \\
\text { 2. An "e" superscript denotes an expectation. } \\
\text { 2. A “*” superscript denotes an equilibrium value. }\end{array}$} \\
\hline
\end{tabular}


with the individual contributions of wage and price adjustments to reestablishing equilibrium to be determined by coefficient values in the dynamic equations.

The main price variable in the U.S. model is a type of absorption index, $P$. The domestic production price, $P_{g}$, is a value-added measure that can be quite volatile at high frequencies, making it a poor indicator of the sluggishness of price adjustment. The application of an adjustment cost approach to price setting follows Rotemberg (1982), who specifies a quadratic cost in changing the price level. Unlike that model, which leads only to sticky adjustment of the price level, the PAC framework also generates gradual adjustment of the inflation rate. This characteristic of price data is also captured by the variant of staggered price setting developed by Fuhrer and Moore (1995).

The equilibrium and dynamic adjustment equations for $P$ are given by equations (10) and (11).

$$
\begin{aligned}
& P_{t}^{*}=\left(P_{g, t}^{*} X_{g, t}+P_{o, t} X_{o, t}\right) / X_{t} \\
& \Delta p_{t}= \begin{array}{l}
0.101\left(p^{*}-p\right)_{t-1}+0.376 \Delta p_{t-1}+0.191 \Delta p_{t-2} \\
(3.7)
\end{array} \\
&+ 0.433 E_{t-1} \sum_{i=0}^{\infty} f_{p, i} \Delta p_{t+i}^{*}-.00003 E_{t-1} \sum_{i=0}^{\infty} g_{p, i} U_{t+i} \\
&+ 0.271 \omega_{e, t-1} \Delta\left(p_{e, t} / p_{b, t}\right)-0.047 \omega_{e, t-2} \Delta\left(p_{e, t-1} / p_{b, t-1}\right)
\end{aligned}
$$

$$
\text { span: 63q1-94q4 } \quad \mathrm{R}^{2}: \quad .88 \quad \text { SEE: } \quad .0025
$$

The dynamic price equation gives a bit more weight to past price inflation than to expected cost increases. A vertical long-run Phillips curve is imposed-the coefficients on lagged and future inflation jointly sum to one-by requiring that $b_{1}=0$ in the cost equations (1) for both prices and wages. The target price level is permitted to vary with the cyclical state of the economy, which results in the inclusion of the expected unemployment rate in equation (11). The target price is estimated to vary procyclically. ${ }^{6}$ The equation also

\footnotetext{
${ }^{6}$ The forward weights on expectations of stationary variables, $g_{p, i}$, have a slightly different profile than the weights on the expectations of differences of nonstationary variables, $f_{p, i}$; both sets are normalized to sum to one.
} 
contains the growth rate of the real price of energy whose contemporaneous value enters highly significantly. This variable lies outside the PAC framework, and its significance likely indicates that the speed of adjustment of prices of energy-intensive products such as retail gasoline is faster than that of many other goods.

The wage adjustment equation (12) shows wages to be more inertial than prices. The error-correction coefficient is smaller, and the weights on lagged and expected inflation are shifted more toward the former. These coefficient differences are reflected in a mean expectations lead that is more than twice as long for wages ( 8.7 quarters) than for prices (3.3 quarters).

$$
\begin{aligned}
& \Delta w_{t}=0.030\left(w^{*}-w\right)_{t-1}+0.231 \Delta w_{t-1}+0.210 \Delta w_{t-2}+0.210 \Delta w_{t-3}(12)
\end{aligned}
$$

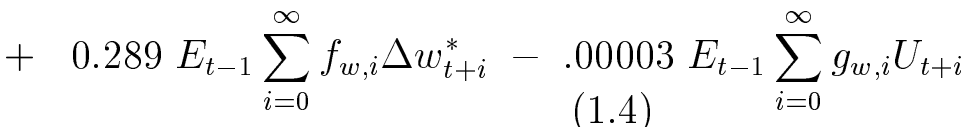

$$
\begin{aligned}
& \text { - } 0.009 D_{w p c, t}+1.40 \operatorname{SITAX} X_{t}+0.028 \Delta w_{m i n, t} \\
& \text { span: 63q1-94q4 } \quad \mathrm{R}^{2}: \quad .82 \quad \text { SEE: } \quad .0028
\end{aligned}
$$

The target wage also varies procyclically, but the coefficient on the expected unemployment rate is estimated with less precision than is the corresponding coefficient in the price equation. The equation for hourly compensation contains three non-PAC variables, each of which is highly significant-a dummy for wage and price controls, the rate of growth of employer social insurance taxes, and the rate of increase of the real minimum wage.

The presence of higher-order adjustment costs in the price and wage equations-as indicated by the economically significant coefficients on the lagged dependent variablesimplies that both price and wage inflation are sticky. One consequence of this property is that policy actions to lower the rate of inflation require that the unemployment rate rise above its equilibrium for some period of time, even if firms and households form expectations rationally and are aware of the policy shift.

Investment. The final sector presented is investment in producers' durable equipment. The equilibrium condition (13) is the standard first-order condition for capital given a 
Cobb-Douglas production function, translated into a steady-state condition for investment. ${ }^{7}$

$$
\begin{aligned}
& i_{t}^{*}=x_{b, t}+z_{t}+\log \left(\Delta \bar{x}_{b, t}+\delta_{t}\right) \\
& \Delta i_{t}=0.066\left(i^{*}-i\right)_{t-2}+0.008 \Delta i_{t-1}+.254 \Delta i_{t-2} \\
& +\underset{(8.2)}{0.499 E_{t-2}} \sum_{j=-1}^{\infty} f_{i, j} \Delta i_{t+j}+\underset{(2.2)}{1.275 E_{t-2}} \sum_{j=-1}^{\infty} g_{i, j} \Delta x_{b, t+j} \\
& +0.152 \Delta \text { cflow }_{t}+0.066 \Delta \text { cflow } \text { fl }
\end{aligned}
$$

Two aspects of the dynamic investment equation (14) are noteworthy. First, firms are heterogeneous, with some following the optimizing specification and others constrained by cash flow. According to the equation, 22 percent of investment is undertaken by firms that are constrained - as indicated by the sum of coefficients on cash flow growth - and the remaining 78 percent by firms that optimize. The optimizing share is embodied in the coefficients on the adjustment and expectations variables. Second, the optimizing firms have a one-quarter delivery lag, indicated by the time dating of the error-correction term and the expectations variables.

Overview of the U.S. Equations. The U.S. sector contains about 40 behavioral equations of which about one-third have been estimated with the cost of adjustment specification or as present values and thus contain explicit expectations. In addition to the four equations discussed above, the PAC framework is used for consumption, two categories of consumer durables, aggregate labor hours, and dividends. Equations for three long-term interest rates and the value of corporate stock use a present value specification. Equations for exports, imports, labor supply, hours per worker, nonresidential structures, and a number of other variables are estimated using traditional methods without explicit expectations.

Looking first at the PAC equations, which are summarized in the upper block of table 2 ,

\footnotetext{
${ }^{7}$ Because BEA has yet to publish data for real capital stocks that are consistent with the new chainweighted measures of real investment, the equilibrium conditions for business and household investment take this flow form.
} 
Table 2: Summary of Key FRB/US Equations

\begin{tabular}{|c|c|c|c|c|c|c|}
\hline \multirow[t]{3}{*}{ Equation } & \multicolumn{3}{|c|}{ Equilibrium Component } & \multirow{2}{*}{\multicolumn{2}{|c|}{$\begin{array}{c}\text { Adjustment Cost } \\
\text { Component }\end{array}$}} & \multirow{3}{*}{$\begin{array}{l}\text { Additional } \\
\text { Dynamic } \\
\text { Terms }\end{array}$} \\
\hline & \multicolumn{2}{|c|}{ Variables } & \multirow{2}{*}{$\begin{array}{l}\text { Mean } \\
\text { Lead }^{1}\end{array}$} & & & \\
\hline & Nonstationary & Stationary & & Order & Mean Lead $^{2}$ & \\
\hline & & $(2)$ & $(3)$ & $(4)$ & (5) & $(6)$ \\
\hline Agg. consumption & $Y^{e}, V$ & $\tilde{y}$ & 16.0 & 2 & 3.8 & Liq. constr. \\
\hline Motor vehicles & $Y^{e}, V, P_{i} / P, T$ & $\tilde{y}, C C$ & 16.0 & 2 & 2.5 & Accel. \\
\hline Other durables & $Y^{e}, V, P_{i} / P, T$ & $\tilde{y}, C C$ & 16.0 & 2 & 3.7 & Accel. \\
\hline Housing & $Y^{e}, V, T$ & $C C$ & 16.0 & 2 & 4.7 & Accel. \\
\hline Equip. inv. & $X_{b}, C C, \delta$ & $\Delta x$ & & 3 & 8.6 & Cash flow \\
\hline Inventory inv. & $X_{b}$ & & & 4 & 2.6 & \\
\hline Agg. hours & $X_{g}, T$ & & & 2 & 2.9 & \\
\hline Price & $W, \rho, P_{e}$ & $\bar{U}$ & & 3 & 3.3 & \\
\hline Wage & $P, \rho, P_{e}$ & $U$ & & 4 & 8.7 & \\
\hline Dividends & $\Pi$ & & & 2 & 4.4 & \\
\hline & Fundamental & Variables & & & & \\
\hline 5-yr. bond rate & $R_{s}^{e}, \tilde{y}$ & & 8.9 & 0 & & \\
\hline 10-yr. bond rate & $R_{s}^{e}, \tilde{y}$ & & 17.1 & 0 & & \\
\hline Corp. bond rate & $R_{s}^{e}, \tilde{y}$ & & 39.2 & 0 & & \\
\hline Stock Market & $R_{L}, \pi^{e}$ & $\Delta d^{e}$ & 49.0 & 0 & & \\
\hline $\begin{array}{l}\text { Notes: } \\
\text { 1. Mean lead (qual } \\
\text { 2. Mean lead (qua }\end{array}$ & S & Ot taiget & toic & 10 anje & $s, \pi$ & \\
\hline
\end{tabular}


the estimated order of adjustment costs, which is reported in column 4 and corresponds to the value of $m$, ranges from 2 to 4 . Thus, compared with the standard LQ specification $(m=1)$, all nonfinancial equations contain added adjustment parameters-or "higherorder" adjustment costs. ${ }^{8}$ Mean leads of expectations associated with adjustment dynamics (column 5) range up to 8 quarters. Mean adjustment lags (not shown) are similar to the mean leads. Not surprisingly, adjustment dynamics are most rapid for aggregate hours and inventories. Motor vehicle purchases also respond quickly. Equipment investment and wages display the most sluggish dynamics.

The magnitudes of adjustment costs as measured by the mean adjustment lags are somewhat smaller than comparable results reported in the literature (Rotemberg, 1982; Blinder, 1986; and Schuh, 1996). Two other general characteristics of the PAC equations are important to note (Brayton and Tinsley, 1996). Only about one-quarter of the equations fail tests of rational expectations overidentifying restrictions at conventional significance levels, and an equally small percentage show significant evidence of serially correlated residuals. The generally favorable nature of the test outcomes is a consequence of the inclusion of higherorder adjustment costs.

Several of the nonfinancial equations combine optimizing behavior, subject to adjustment frictions, with other types of behavior. The case of equipment investment, in which some firms are constrained by available cash flow, has been discussed. Similarly, in the spirit of Campbell and Mankiw (1989), the equation for aggregate consumption, which includes the service flow from the stock of durables, allows for the presence of both optimizing and rule-of-thumb or liquidity-constrained households. The estimated shares of consumption by the two groups are .90 and .10 , respectively. Abstracting from the existence of rule-of-thumb consumers, the consumption sector would still violate Ricardian equivalence, because optimizing households use a high 25 percent annual discount rate in calculating expected income. ${ }^{9}$ Another aspect of the consumer's optimization problem is that labor supply is taken as exogenous, so there is no explicit substitution between labor and leisure.

\footnotetext{
${ }^{8}$ In the case of other consumer durables, however, the single extra cost parameter is not statistically significant.

${ }^{9}$ The discount rate of 25 percent corresponds to a mean lead of 16 quarters in the calculation of expected income, as indicated in column 3 of table 2. Estimation results deteriorate significantly at low values of the discount rate. As shown by Muelbrauer and Lattimore (1995), a theoretical rationale for a high discount rate is the presence of risk aversion in the face of idiosyncratic income uncertainty.
} 
Equations for three long-term bond rates are specified according to the expectations theory of the term structure. In each equation, the principal explanatory variable is a weighted average of short-term interest rates expected to prevail over the maturity of the bond, with weights given by the maturity of the bond and the sample mean of its yield, as in Shiller (1979). Each bond yield is estimated to have a time-varying term premium that is countercyclical. The equation for the value of the stock market is based on the Campbell-Shiller (1989) log linearization of the discounted value of expected dividends, assuming a constant equity premium. The residuals of the bond and stock market equations contain substantial serial correlation. As in the case of nonfinancial equations, expectations required to estimate the financial equations are generated by VARs.

\subsection{The Non-U.S. Countries}

The design and specification of the foreign sectors of FRB/WORLD follows from two research projects at the International Finance Division at the Fed. The first was the development of a small multi-country model, along the lines of the models of Taylor (1993b) and the IMF's Multimod (Masson et al., 1988). This four-region model (U.S., Germany, Japan, and ROW), named MX-3, was constructed with forward-looking expectations in equations for prices, interest rates, and exchange rates (Gagnon, 1991). The second was the direct incorporation of forward-looking behavior into a version of the MCM model. Levin (1996) discusses the structure and properties of FRB/MCM.

For the G7 countries excluding the United States (Canada, France, Germany, Italy, Japan, and the United Kingdom), a consistent set of dynamic specifications is employed, as summarized in Table 3. Except for the consumption and investment equations, equation coefficients are calibrated, not estimated. The level of aggregation is about the same or, in some cases, somewhat greater than that for the U.S. economy. For example, consumption expenditures are not disaggregated. Expectations enter explicitly in the definition of real interest rates, the pricing of long bonds, and the determination of exchange rates.

Components of aggregate demand are assumed to follow error-correction or partial adjustment dynamic models. The equilibrium ratio of consumption to either disposable or total income depends on the real interest rate. Equations for residential, non residential, and inventory investment reflect dynamic adjustment towards desired stocks, which depend on the cost of capital. Equilibrium levels of non-fuel goods and non-factor service imports 
Table 3: Summary of Non-U.S. Sectors

\begin{tabular}{|c|c|c|c|c|}
\hline \multirow[t]{2}{*}{ Equation } & \multicolumn{2}{|c|}{ Equilibrium Component } & \multicolumn{2}{|c|}{ Dynamics } \\
\hline & Nonstationary & Stationary & Own Lags & Other factors \\
\hline & $(1)$ & $(2)$ & (3) & $(4)$ \\
\hline Consumption & $Y$ or $X$ & $C C$ & 0 & $\Delta x$ \\
\hline Housing investment/GDP & $K / X$ & $C C$ & $1-4$ & $\Delta x$ \\
\hline Private fixed investment/GDP & $K / X$ & $C C$ & $1-8$ & $\Delta x$ \\
\hline Inventory investment/GDP & $K / X_{s}$ & $C C$ & $1-8$ & $\Delta x_{s}$ \\
\hline Nonfuel goods imports & $X$ & $P_{f}$ & 1 & \\
\hline NFG exports/foreign NFG imports & & TOT & 1 & \\
\hline Price (total output) & $W, P_{e}$ & $\tilde{y}$ & 1 & \\
\hline Contract wage & $W$ & $U$ & 0 & \\
\hline Real money demand & $X$ & $R_{s}$ & 1 & \\
\hline Long bond rate & & $R_{s}^{e}$ & 0 & \\
\hline
\end{tabular}

depend on relative prices and domestic absorption. To ensure balanced global trade, each country's exports are determined by its share of world imports, with the equilibrium share depending on the terms of trade.

Wage setting is based on Taylor's (1980) staggered contracts model, with the contract wage a function of expected future market wages and labor market tightness, as represented by deviations of the unemployment rate from the NAIRU. The market wage is a weighted average of current and past contract wages. The markup of the output price deflator over the wage rate and the domestic oil price varies procyclically. Real interest rates are defined using expectations of changes in the domestic absorption deflator, constructed from the output deflator and relative energy and import prices. Equations for long-term interest rates are based on the expectations model of the term structure with a fixed term premium, and those for nominal exchange rates are uncovered interest parity conditions augmented with a time varying sovereign risk premium.

For the three sectors representing Mexico, the newly industrializing economies, and other OECD countries, a somewhat more simplified and stylized specification is used. Investment is not disaggregated, and calibration is used instead of econometric estimation for all equation coefficients. Finally, for the sectors representing OPEC members and other developing and transition economies, the model is simplified further. 


\section{Full-System Properties}

As mentioned above, the single-equation approach to estimating FRB/WORLD leads to equations which individually have good statistical properties in terms of fit and absence of misspecification. The estimation procedure does not ensure that the resulting system properties will resemble those of the data, however. Tests of system dynamics are important, not only because the main uses of the model involve dynamic simulations but also because such tests may lead to a reexamination of the specifications of particular equations. Not surprisingly, the process of developing FRB/WORLD involved some iterating back and forth between evaluation of system characteristics and revision of specific equations.

A traditional approach to characterizing a model's properties is to examine responses to transitory shocks, and several sets of such responses are presented below. In addition to describing system properties, these simulations are used to evaluate the effects of switching between limited- and full-information assumptions regarding expectations formation and to compare impulse responses of an estimated VAR with those obtained from FRB/WORLD. To provide another view of the model's goodness of fit, moments of historical data are compared with those generated by stochastic simulation.

\subsection{System Responses to Transitory Shocks}

For the simulations in this section, the U.S. monetary authority is assumed to set the federal funds rate according to the equation for that variable in the core part of the expectations VAR used in the U.S. sector, while other central banks set short-term rates according to a Taylor-type (1993a) rule in which the real short rate responds to deviations of output from potential and inflation from its target. The U.S. funds rate equation was estimated over 1963:Q1-1994:Q4. Figure 1 shows the responses of inflation, output, the federal funds rate, and the 10-year government bond rate to a one-quarter, 100-basis point positive shock to the U.S. policy rule. In order to simplify the design of this simulation and the other experiments involving transitory shocks, each simulation of this type is based on the assumption that the long-run inflation objective of monetary policy is unchanged, as are private perceptions of the objective. The U.S. economy's response under model-consistent expectations is shown as the solid line, while the dashed line represents the results under VAR expectations. ${ }^{10}$

\footnotetext{
${ }^{10}$ In this and other simulations of FRB/WORLD, "VAR" expectations denotes the case of limitedinformation expectations based on VARs in the U.S. sector and autoregressions in the other sectors.
} 
Figure 1: One-quarter, 100 basis point shock to funds rate
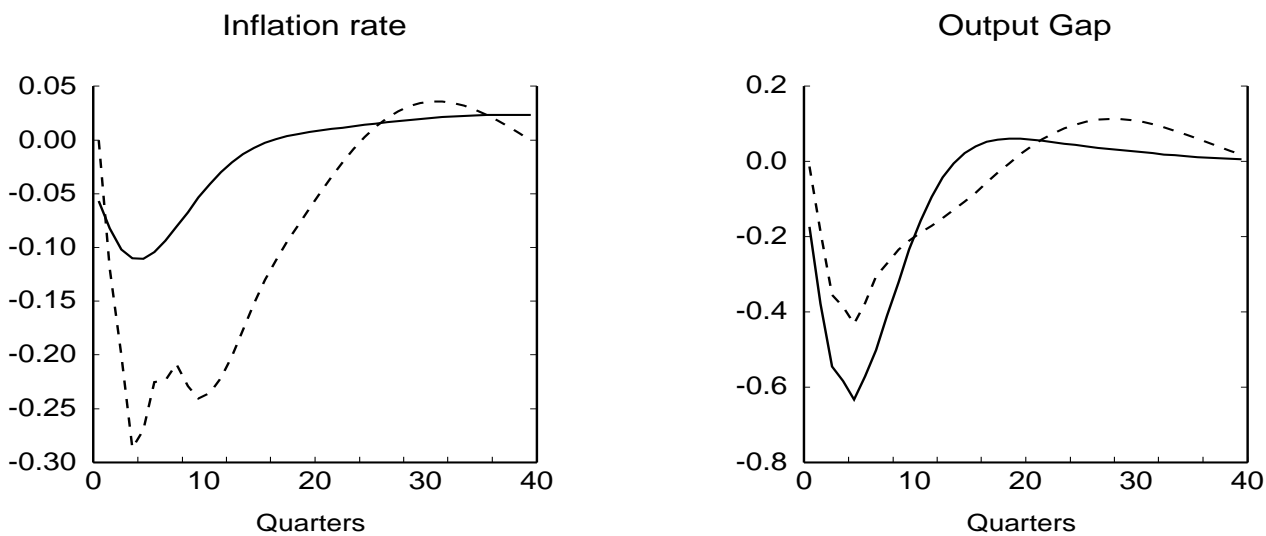

Federal funds rate 10 year government bond rate
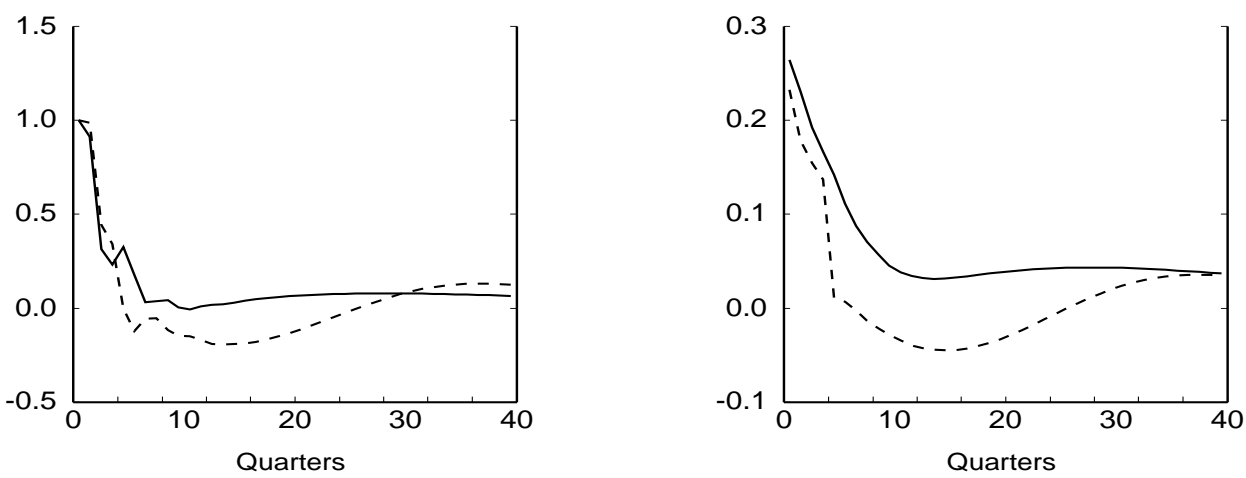

Model-Consistent Exp.

- - VAR Exp.

Results in all instances are displayed as deviations from baseline.

The increase in the nominal federal funds rate generates the expectation of higher funds rates in the future, driving up bond rates. Given the sluggish adjustment of prices, the costs of capital for consumer durables, housing, and business investment rise and the real exchange rate appreciates, causing aggregate demand and output to decline and unemployment to increase. The rise in actual and expected unemployment drives wage and price inflation down. The hump-shaped pattern of the output response is a consequence of the interaction of sluggish adjustment of demand components, the evolution of expectations of future quantities and prices, and the endogenous response of monetary policy after the initial shock. 
Figure 2: Four-quarter, $1 \%$ of GDP Increase in Government Purchases
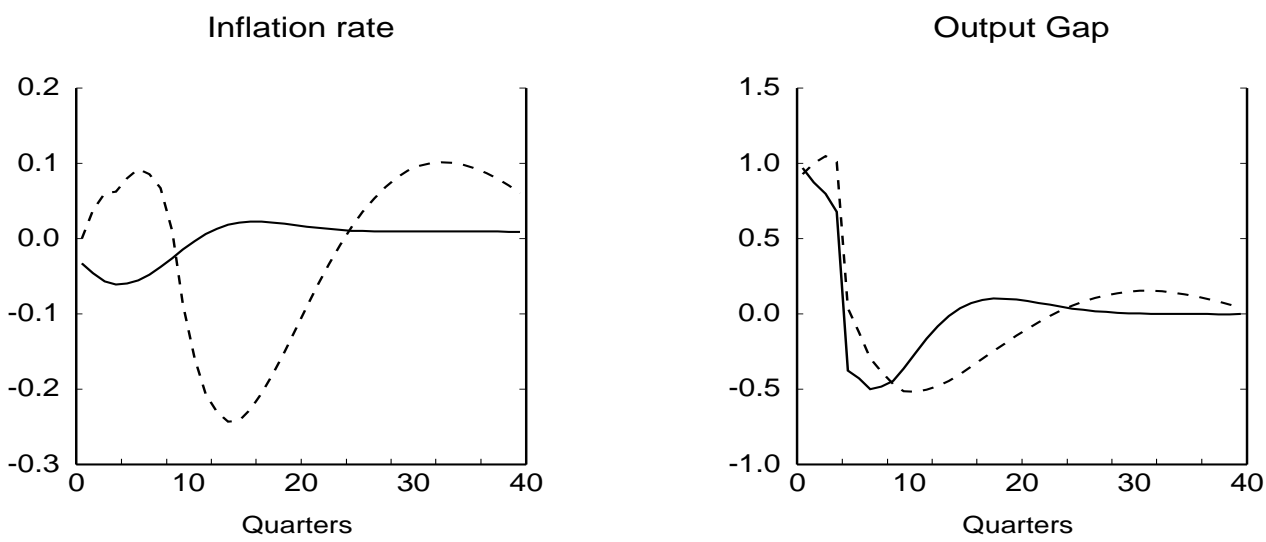

Federal funds rate 10 year government bond rate
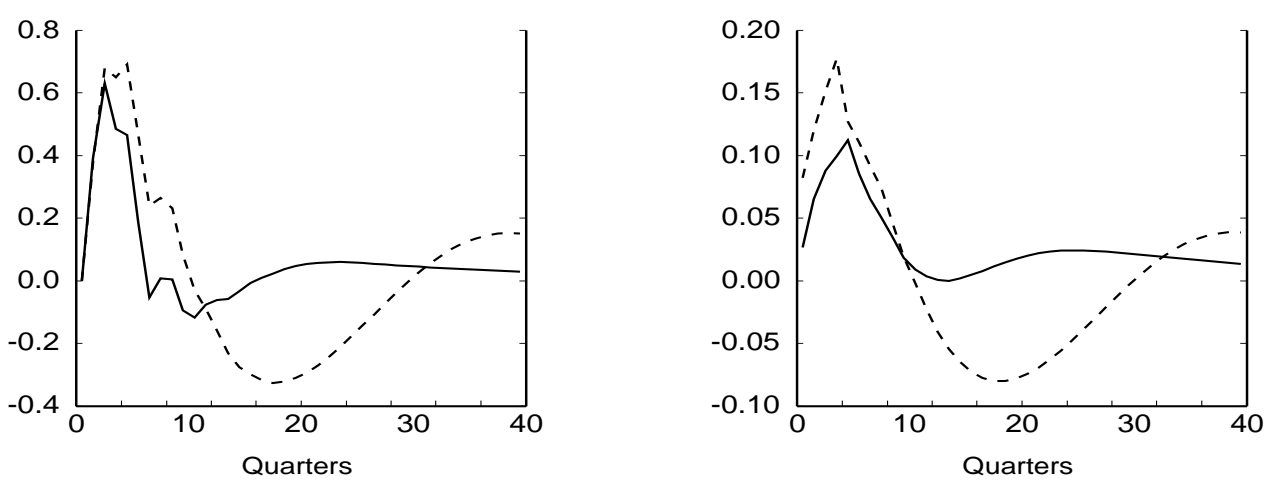

Model-Consistent Exp.

- - VAR Exp.

Our prior was that this experiment should result in outcomes under model-consistent and VAR expectations which are similar. The shock is not unusual in any way, and so the responses of the expectations VAR should mimic those of the full model. In other words, expectations based on the full structure should be about the same as expectations based on the small VAR. Looking at the figure, the simulated outcomes for the output gap and short and long interest rates are in fact quite similar under the two expectations assumptions. However, the peak reduction in inflation under VAR expectations is about three times that under model-consistent expectations. We will return to this issue later.

Figure 2 shows the response to an increase in government purchases, equal to one percent of GDP, lasting one year. The exogenous rise in aggregate demand is initially reflected 
one-for-one in output. Sluggish adjustment of hours implies that much of this initial surge in activity is generated by a temporary up-tick in productivity. The high level of activity leads to an increase in interest rates. The cessation of the spending shock then drives output significantly below baseline as the effects of the rise in interest and exchange rates start to take hold. This overshooting of output is then corrected over time.

The larger movement in the government bond rate under VAR expectations, relative to that under model-consistent expectations, can be traced to differences between the "typical" behavior of output as represented in the expectations VAR and the unusual pattern induced by this particular shock. The four-quarter nature of the spending shock represents an atypical pattern for demand shocks; thus, under VAR expectations agents misinterpret the information contained in the output gap and forecast a rise in output that is more sustained than that which occurs, leading to more dramatic movements in prices and interest rates.

As in the previous experiment, the behavior of inflation is dissimilar under the two expectations assumptions. In fact, the inflation response under rational expectations is negative in response to the boom in spending. This is due to the forward-looking nature of price and wage setting. Although unemployment falls below baseline during the year of the shock, and rises above baseline thereafter, the weighted sum is positive. Thus, a small transitory reduction in inflation results. If the shock were to last longer, the initial response of inflation would in fact be positive because the weighted sum of future unemployment would be negative. The procyclical pattern of inflation observed in the case of VAR expectations can be traced to expectations errors.

\subsection{Comparison with VAR Models}

One test of a properly specified model is its ability to mimic the behavior of data as represented by VAR models. For this purpose, we compare the system response to a funds rate shock under VAR expectations to the impulse response from the VAR used in formulating expectations in the U.S. sector. In order for an experiment of this type to be consistent, one needs to apply the same shock to the two models. This is straightforward to do for a funds rate shock, if we use an ordering assumption to make it orthogonal to other shocks. To extend the comparison to demand and supply disturbances, however, aggregates of the many demand and supply shocks in FRB/US would have to be constructed. 
In Figure 3, the impulse responses of the core expectational VAR are represented by the dashed lines and one standard error bands by the dotted and dash-dotted lines. The solid lines represent the response of FRB/WORLD under VAR expectations; these are taken from Figure 1. In general, the impulse responses of FRB/WORLD for inflation and output are fairly close to those of the VAR. Inflation declines more rapidly in the former, but this difference should be viewed in a positive light. The VAR displays a "price puzzle"inflation initially rises in response to the positive interest rate shock. FRB/WORLD does not contain a structural mechanism for such an effect to occur, though such an effect could enter as a result of the use of the VAR for expectations. Adjusting for this discrepancy, the two paths are very similar. Also included in the figure is a time representation of the movements in the level and slope of the yield curve. This provides a graphical description of how a policy action affects short- and long-term interest rates over time.

\subsection{Comparison of Moments}

The previous experiments used traditional methods to characterize the system properties of the FRB/WORLD model, emphasizing the responses of inflation, output, and interest rates to transitory policy shocks. We now turn to a more general approach to studying system dynamics - one frequently used in the equilibrium business cycle literature- that compares simulated standard deviations and cross correlations for key endogenous variables with comparable statistics calculated using historical data. For computational reasons, this exercise is carried out with FRB/US only. The foreign sectors are replaced by simple equations for the levels of foreign price and output aggregates. Each stochastic simulation lasts 30 years and is based on a bootstrap procedure that draws shocks randomly from the set of historical equation error vectors over 1966:Q1-1995:Q4. ${ }^{11}$ Simulated moments are based on 300 replications. Monetary policy is characterized by the estimated equation for the federal funds rate that is in the expectational VAR. Historical and simulated moments were calculated after low-frequency movements in the actual and simulated data had been removed with the Hodrick-Prescott (HP) filter.

Historical standard deviations of key variables and their correlations with real GDP are

\footnotetext{
${ }^{11} \mathrm{~A}$ total of 50 equations are shocked, including a number of time series equations specially added in this exercise for variables, such as the price of oil, that are normally exogenous; remaining exogenous variables are held constant. Shocks are drawn from the set of historical equation residuals obtained from estimation of each equation with the VAR-based proxies for expectations.
} 
Figure 3:

VAR Estimated: 1963-1994
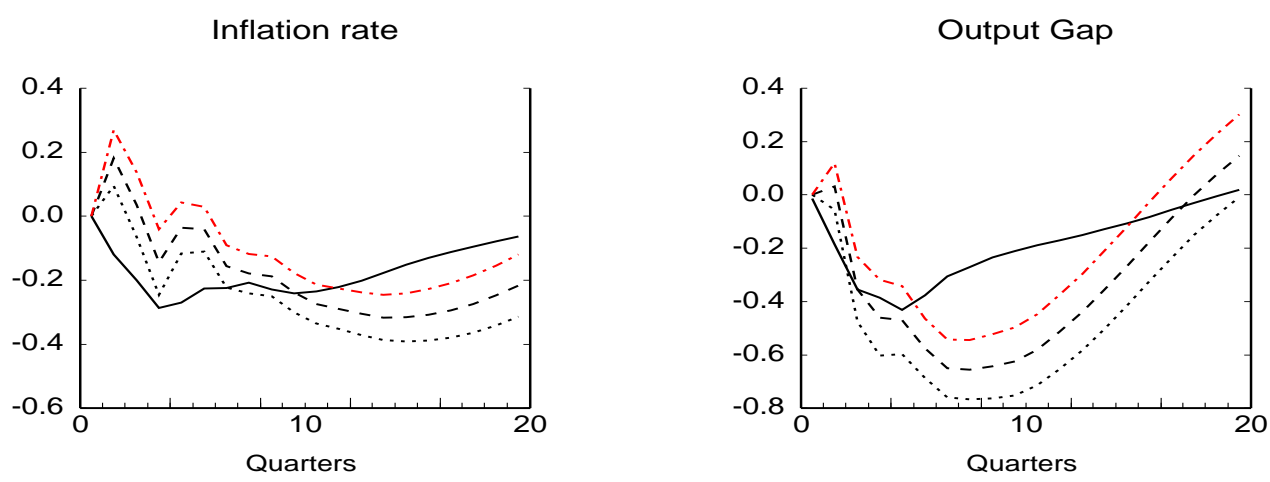

Federal funds rate
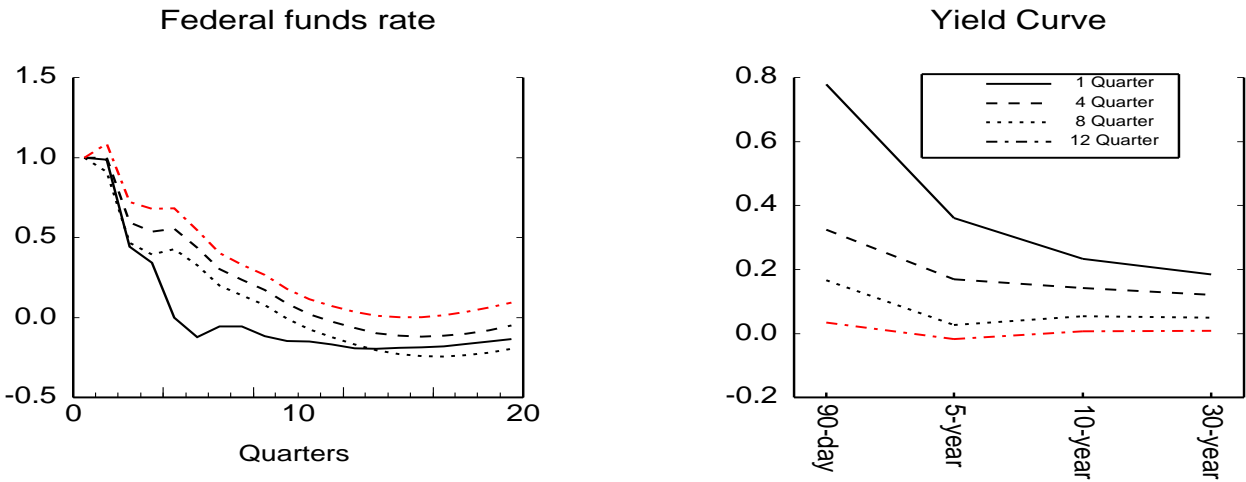

\begin{tabular}{|cccc|}
\hline$-\cdots$ & FRB/WORLD & $-\cdots$ & VAR \\
$\cdots \cdots$ & upper band & $\cdots \cdots$ & lower band \\
\hline
\end{tabular}

shown in table 4, as are corresponding simulated statistics under VAR and model-consistent expectations. The same set of shocks were used for each expectational assumption. For the simulated moments, two asterisks denote instances where the historical statistic is more than two standard deviations from the simulated value, while a single asterisk indicates differences that are between one and two standard deviations. The standard deviations are based on the distribution of statistics over the set of simulations.

The results in the table provide considerable information about the ability of FRB/US to match the dynamic properties of historical data, and about the effects of different expectations assumptions on simulated dynamics. Under both expectations assumptions, the model matches the historical correlations of output with leads and lags of key variables 
Table 4: Moment Comparison

\begin{tabular}{lllllllll}
\hline & & \multicolumn{7}{c}{ Cross Correlation of GDP with } \\
\cline { 3 - 8 } Variables $\mathrm{S}$ & dev. & $\mathrm{x}(\mathrm{t}-4)$ & $\mathrm{x}(\mathrm{t}-2)$ & $\mathrm{x}(\mathrm{t}-1)$ & $\mathrm{x}(\mathrm{t})$ & $\mathrm{x}(\mathrm{t}+1)$ & $\mathrm{x}(\mathrm{t}+2)$ & $\mathrm{x}(\mathrm{t}+4)$ \\
\hline
\end{tabular}

Historical Data (1966-95)

\begin{tabular}{ll|rrr|r|rrrr} 
GDP & 1.70 & 0.24 & 0.68 & 0.87 & 1.00 & 0.87 & 0.68 & 0.24 \\
Nondurables \& Services & 0.89 & 0.43 & 0.76 & 0.85 & 0.84 & 0.72 & 0.55 & 0.14 \\
Durable Consumption & 5.08 & 0.51 & 0.76 & 0.83 & 0.82 & 0.60 & 0.39 & -0.07 \\
Business Fixed Invest. & 4.88 & -0.14 & 0.32 & 0.58 & 0.80 & 0.88 & 0.86 & 0.57 \\
Inventory Stock & 1.53 & -0.22 & 0.08 & 0.30 & 0.57 & 0.76 & 0.85 & 0.75 \\
\hline Hours & 1.91 & 0.04 & 0.49 & 0.72 & 0.89 & 0.90 & 0.82 & 0.49 \\
Inflation Rate & 1.40 & -0.37 & -0.07 & 0.09 & 0.27 & 0.39 & 0.47 & 0.64 \\
Real Wage & 0.50 & 0.36 & 0.55 & 0.58 & 0.60 & 0.50 & 0.36 & -0.04 \\
Federal Funds Rate & 2.10 & -0.57 & -0.23 & 0.08 & 0.35 & 0.50 & 0.56 & 0.55 \\
10 Year Bond Rate & 0.94 & -0.50 & -0.36 & -0.19 & -0.02 & 0.06 & 0.10 & 0.13
\end{tabular}

\section{Simulated Data: VAR Expectations}

\begin{tabular}{ll|lll|l|lll} 
GDP & $1.29 * *$ & 0.14 & $0.60^{*}$ & $0.80^{*}$ & 1.00 & $0.80^{*}$ & $0.60^{*}$ & 0.14 \\
Nondurables \& Services & 0.92 & $0.21^{*}$ & $0.56^{*}$ & $0.69^{*}$ & $0.75^{*}$ & 0.63 & 0.46 & 0.10 \\
Durable Consumption & 4.53 & $0.28^{*}$ & $0.59^{*}$ & $0.68^{*}$ & $0.73^{*}$ & $0.48^{*}$ & $0.24^{*}$ & $-0.21^{*}$ \\
Business Fixed Invest. & 4.18 & -0.04 & 0.25 & 0.43 & $0.63^{*}$ & $0.70^{*}$ & $0.67^{*}$ & $0.38^{*}$ \\
Inventory Stock & $1.30^{*}$ & -0.25 & -0.10 & $0.05^{*}$ & $0.31^{*}$ & $0.49 *$ & $0.58^{*}$ & $0.54^{*}$ \\
\hline Hours & $1.35^{*}$ & 0.02 & 0.34 & $0.53^{*}$ & $0.74 *$ & $0.72^{*}$ & $0.64 *$ & $0.30^{*}$ \\
Inflation Rate & 1.48 & $-0.12^{*}$ & 0.03 & 0.16 & 0.28 & 0.34 & 0.35 & $0.26^{*}$ \\
Real Wage & $0.65^{*}$ & $0.06^{*}$ & $0.23^{*}$ & $0.27^{*}$ & $0.31^{*}$ & $0.25^{*}$ & $0.15^{*}$ & -0.03 \\
Federal Funds Rate & $1.68^{*}$ & $-0.45^{*}$ & -0.30 & $-0.11 *$ & $0.18^{*}$ & 0.40 & 0.45 & 0.45 \\
10 Year Bond Rate & $0.75^{*}$ & -0.39 & -0.35 & -0.24 & -0.06 & 0.04 & 0.12 & 0.20
\end{tabular}

\begin{tabular}{ll|lll|l|lll} 
Simulated Data: Model-Consistent Expectations \\
GDP & $2.09^{*}$ & 0.17 & 0.67 & 0.86 & 1.00 & 0.86 & 0.67 & 0.17 \\
Nondurables \& Services & $1.43^{* *}$ & $0.18^{*}$ & $0.66^{*}$ & 0.84 & $0.92^{* *}$ & $0.82^{*}$ & 0.64 & 0.21 \\
Durable Consumption & $6.54^{*}$ & $0.21^{* *}$ & $0.66^{*}$ & 0.82 & $0.91^{* *}$ & $0.74^{* *}$ & $0.52^{*}$ & 0.04 \\
Business Fixed Invest. & $4.05^{*}$ & -0.07 & 0.26 & 0.45 & $0.64^{*}$ & $0.71^{*}$ & $0.67^{*}$ & $0.37^{*}$ \\
Inventory Stock & 1.60 & -0.16 & 0.17 & 0.36 & 0.59 & 0.72 & 0.76 & $0.60^{*}$ \\
\hline Hours & 2.10 & 0.08 & 0.55 & 0.75 & 0.90 & 0.86 & $0.74^{*}$ & $0.32^{*}$ \\
Inflation Rate & $1.20^{*}$ & -0.30 & $-0.26^{*}$ & $-0.15^{*}$ & $0.01^{* *}$ & $0.13^{*}$ & $0.17^{* *}$ & $0.16^{* *}$ \\
Real Wage & $0.65^{*}$ & $-0.07^{*}$ & $-0.08^{* *}$ & $-0.08^{* *}$ & $-0.05^{* *}$ & $-0.06^{* *}$ & $-0.06^{*}$ & -0.04 \\
Federal Funds Rate & 2.21 & $-0.34^{*}$ & -0.37 & $-0.30^{* *}$ & $-0.17^{* *}$ & $0.03^{* *}$ & $0.20^{*}$ & $0.31^{*}$ \\
10 Year Bond Rate & $0.75^{*}$ & -0.52 & $-0.60^{*}$ & $-0.51^{* *}$ & $-0.31^{*}$ & -0.08 & 0.10 & $0.31^{*}$ \\
\hline
\end{tabular}


relatively well. However, the simulated standard deviations of most series are somewhat larger under model-consistent expectations than under VAR expectations.

Among the correlations, a few differences do stand out and may suggest aspects of equation specification that are inconsistent with the data. In the historical data, the pattern of correlations of lags and leads of consumption of nondurables and services with GDP is skewed toward the lags. That is, preceeding consumption values are more highly correlated with GDP than those that succeed. This asymmetric pattern is absent in the simulated correlations under model-consistent expectations and present to only a minor degree under VAR expectations. For business fixed investment, the pattern of historical correlations with GDP is the reverse of that of consumption, with correlations being stronger for leads of investment than for lags. Although FRB/US matches the qualitative nature of this asymmetry, it understates the magnitude of the skewness for both expectations assumptions.

The most striking contrast between expectations assumptions is found in the wage and price sector. Recall that disparities between the simulated behavior of inflation under the two expectations assumptions were also found in the simulations of the two transitory policy shocks. Under VAR expectations, the match between the simulated moments of price inflation and those from historical data is close. The simulated real product wage is, however, slightly less procyclical than it is historically. On the other hand, the outcome under model-consistent expectations is far less favorable. In this case, the real wage is slightly countercyclical and the correlations across time of price inflation with output are generally inconsistent with the historical correlations. These differences suggest two conclusions: The wage-price block under model-consistent expectations does not fully capture the dynamics of wages and prices; and the VAR-based measures of expectations in the wage and price block differ from the reduced-form behavior of the full structure of FRB/US.

\section{Policy Evaluation}

To the extent that the specifications of intertemporal decision making and expectations formation in the new model are accurate depictions of reality, it is not subject to the Lucas critique and can be legitimately used to analyze the consequences of shifts in policy. In addition, the flexible approach to expectations formation and the incorporation of learning into the expectations process makes it possible to analyze more fully policy issues such as 
the costs of disinflation and the effects of fiscal consolidation. Two sets of simulations are used to illustrate these capabilities. ${ }^{12}$

\subsection{Disinflation and Policy Credibility}

We first consider a monetary policy shift that aims to permanently reduce the inflation rate by one percentage point. Any number of paths for interest rates can achieve this objective; in the simulations that follow, monetary policy follows a rule for the federal funds rate that is consistent with the planned reduction in inflation, but responds to transitory movements in output and inflation using an equation estimated for the period since late 1979 . We consider two cases of policy credibility as reflected in the behavior of long-run inflation expectations. In the first case of "perfect credibility," the private sector recognizes and fully believes that the announced disinflationary policy will occur as planned. In the second case of "learning," the private sector only slowly adjusts its views about the probability that the full disinflationary program will be carried out. In the latter case, the rate of adjustment is $5 \%$ per quarter, so that long-run inflation expectations have fallen by one-half of one percentage point after 3-1/2 years. This rate of "learning" is consistent with the fall in long-run expectations as measured by surveys during the disinflation of the 1980's.

Figure 4 shows the consequences of a credible policy of disinflation. Higher-order costs of adjustment in wages and prices imply that inflation is sticky and that lowering the inflation rate necessitates opening up an unemployment gap. Still, in the case of perfect credibility policy, the cost can be reduced to a trivial amount if the action to reduce the rate of inflation is carried out very gradually or announced far in advance. For the experiments considered here, however, the policy change is carried out rather aggressively-with inflation falling by the intended amount in about two years-and the sacrifice ratio (cumulative annual increase in the unemployment rate divided by the percentage point decrease in the inflation rate, computed at the end of the tenth year) under model-consistent expectations (2.0) is in fact a bit higher than that under VAR expectations (1.6). For this particular experiment, the forecasting errors that agents make under VAR expectations actually help to reduce the cost of disinflation.

The results of relaxing the assumption of perfect credibility of the disinflationary policy

\footnotetext{
${ }^{12}$ In another application, Williams (1997) studies the stabilization characteristics of monetary policy rules using FRB/US under model-consistent expectations.
} 
Figure 4:

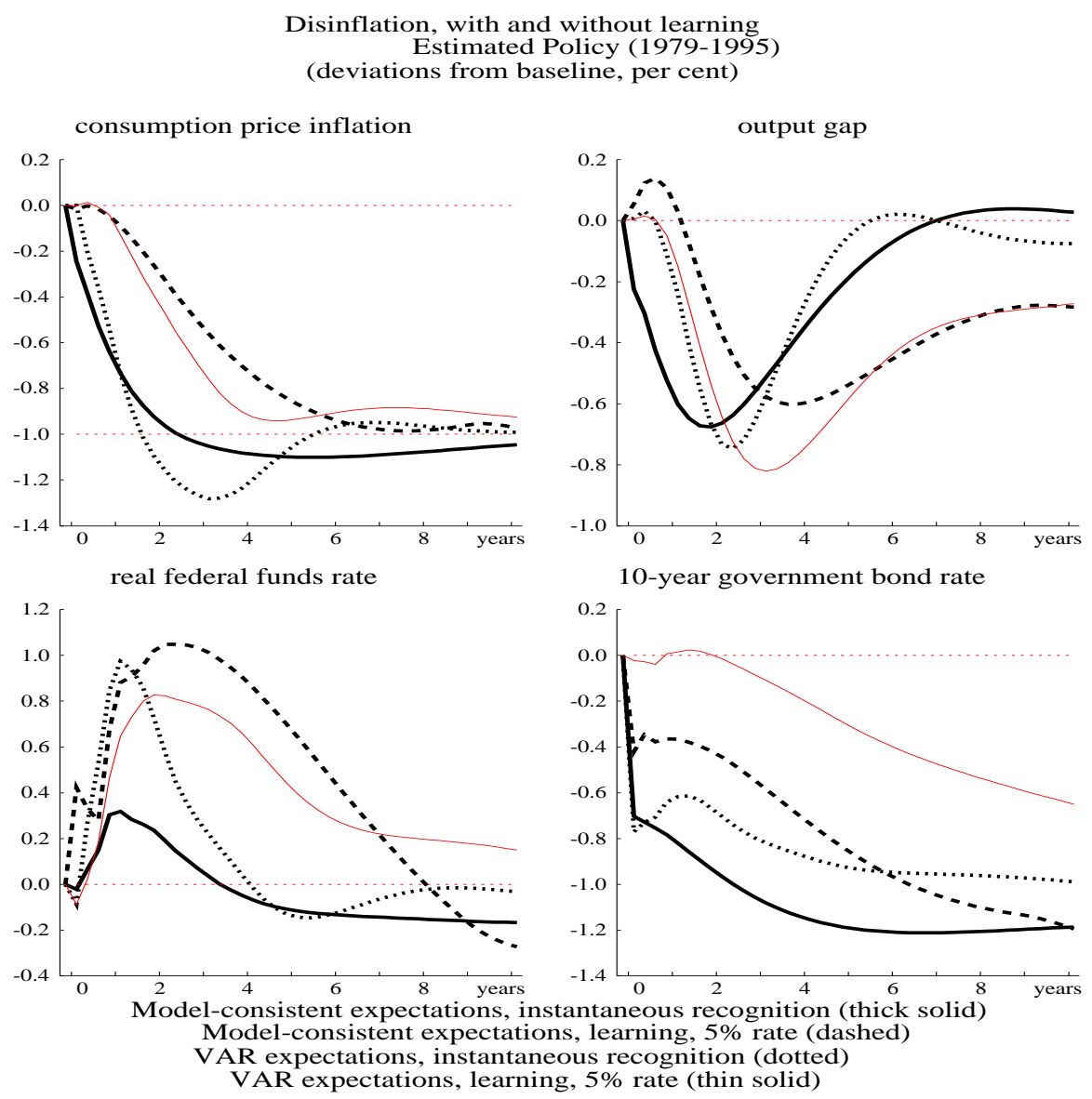

are also shown in Figure 4. Inflation declines more gradually in this case. Also, the rapid decline in bond rates in the case of perfect credibility is absent under imperfect credibility. Bond traders, like other agents in the economy, only gradually adjust their views about the long-run objectives of policy. The higher real interest rates generated by the disinflationary policy lead to losses of output that are significantly greater than those under perfect credibility. In terms of the sacrifice ratio, the effect of imperfect credibility is to increase the cost of disinflation from 1.6 to 2.9 for VAR expectations and from 2.0 to 2.5 for model-consistent expectations. Under imperfect credibility of monetary policy, the extra leverage from a full and immediate reduction in long-run inflationary expectations is absent. Thus, the monetary authority must dampen aggregate demand and lower observed inflation through higher 
real interest rates in order to convince the private sector of its determination to disinflate.

\subsection{Shifts in Foreign Macroeconomic Policy}

We consider a scenario of current policy interest, fiscal consolidation in the foreign G-7 economies, to illustrate the operational use of the FRB/WORLD model. ${ }^{13}$ Compared with a baseline in which spending reductions would be implemented gradually over seven years starting in 1999, the scenario assumes that the reductions start in 1997 and are completed in only two years to help ensure that the E.U. members meet the Maastricht criteria for monetary union, and to reflect similar actions under consideration in Canada and Japan. Thus, this experiment measures the impact on the U.S. economy of a tightening in foreign fiscal policy that commences in 1997, reaches its peak in 1998, and after gradually diminishing ends in 2005.

The peak cuts in government spending are 1 percent of GDP in Canada, France, the U.K., and Germany; 1-1/2 percent in Japan; and 4 percent in Italy. We assume that the monetary authorities in the U.S., Canada, Germany and Japan set interest rates according to Taylor's (1993a) rule, and that the French franc, Italian lira, and British pound are pegged to the Deutschmark.

The simulation results for this experiment are shown in figure 5. As seen in the bottom left panel, the government spending cuts cause foreign GDP (aggregated by U.S. trade weights) to drop about $3 / 4$ percent relative to baseline toward the end of the second year of the simulation, before gradually returning to baseline. The decline in foreign output is similar under VAR and model-consistent expectations. In contrast, the contraction of U.S. GDP and reduction in U.S. inflation is sensitive to the expectations assumption, with the effects being larger in magnitude in the limited information case, though still far short of the decline abroad. U.S. monetary policy dampens the impact of falling net exports through a reduction of about $20-25$ basis points in the federal funds rate. Foreign interest rates decline by a larger amount, in response to the larger decline in foreign output, and hence the foreign exchange value of the dollar appreciates.

\footnotetext{
${ }^{13}$ Bowman and Rogers (1997) provide a detailed analysis of FRB/WORLD model simulations related to foreign fiscal consolidation.
} 


\section{Conclusions}

Large scale macro models are by their nature slow to evolve. This is both a blessing and a curse. Changes in models respond to shifts in the consensus view, as opposed to that of the latest cutting edge research. This helps avoid the pitfall of constantly changing policy advice and interpretation. On the other hand, models can easily become out of date and irrelevant.

At the time of their original development, the Fed models reflected the received wisdom on macroeconomic and international linkages. This consensus started to shift in the 1970 's towards a focus on rational expectations and intertemporal optimization. As a new consensus developed in the late 1980's and early 1990's, the Fed models were redesigned to incorporate, at least partially, the evolving new paradigm.

By many measures this effort has been a success. The model fits the data well, yet retains a theoretical structure that can be used to investigate pertinent policy and general macroeconomic issues. The flexible treatment of expectations formation and learning opens a wide range of interesting issues for quantitative monetary and fiscal policy analysis. Still, the new FRB model is not the stochastic general equilibrium model some have called for. For example, optimization and estimation is conducted on a single equation basis, ignoring some of the linkages between decisions by firms and households. Such an approach in a large-scale model is currently computationally prohibitive and must remain a part of the third generation redesign. 
Figure 5: Foreign Fiscal Consolidation

Inflation rate

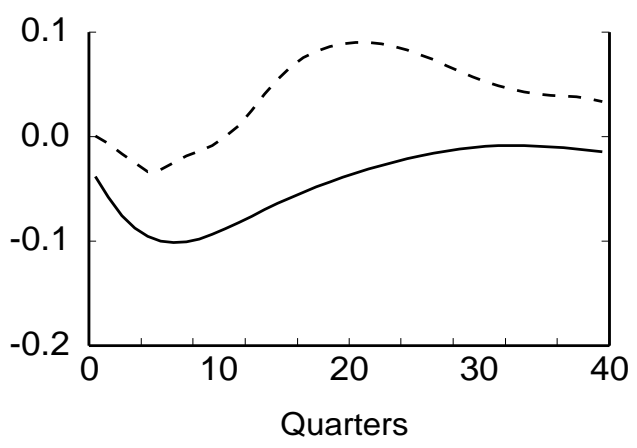

Federal funds rate

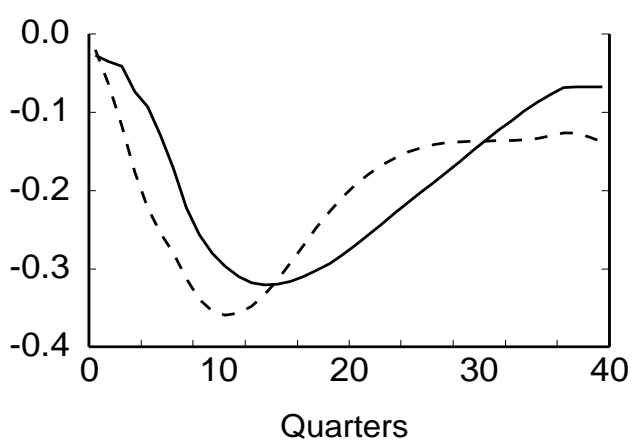

Foreign GDP (\%)

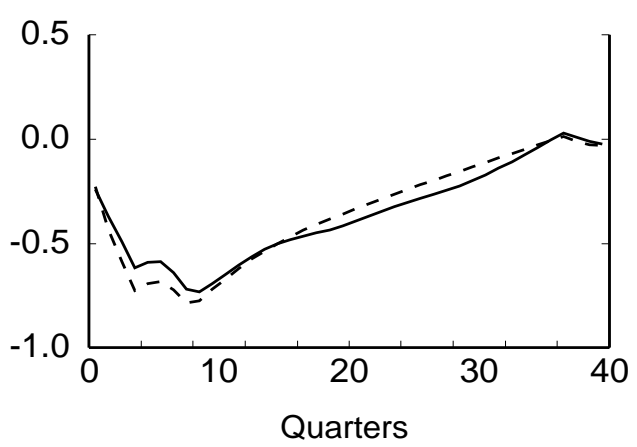

Output Gap

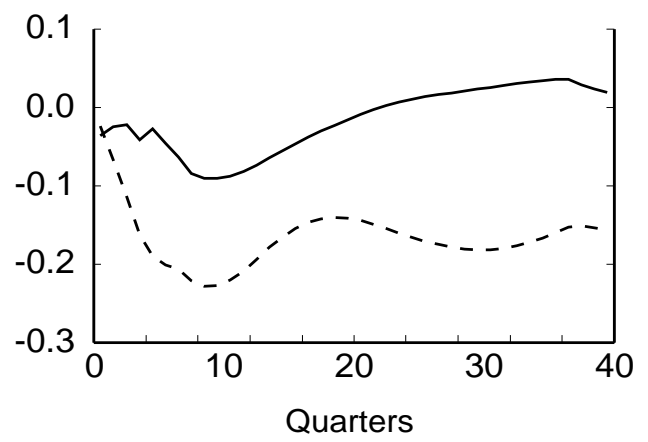

10 year government bond rate

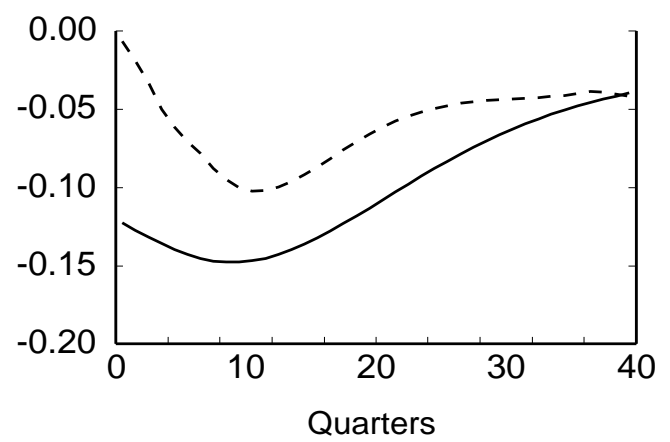

Real Exchange Rate (Foreign/US) (\%)

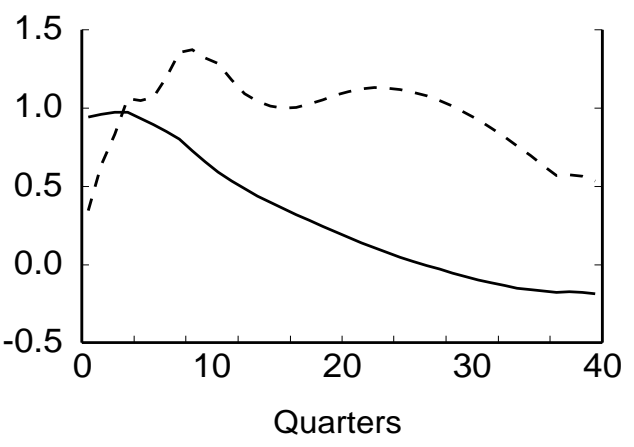




\section{References}

Anderson, G. and Moore, G. (1985) A Linear Algebraic Procedure for Solving Linear Perfect Foresight Models. Economics Letters, 17: 247-52.

Ando, A. and Brayton F. (1995) Prices, Wages, and Employment in the US Economy: A Traditional Model and Tests of Some Alternatives. The Natural Rate of Unemployment: Reflections on 25 Years of the Hypothesis, ed. R. Cross. Cambridge University Press.

Ando, A. and Modigliani F. (1969) Econometric Evaluation of Stabilization Policies. American Economic Review, 59: 296-314.

Ando, A. and Rasche, R. (1971) Equations in the MIT-PENN-SSRC Econometric Model of the United States. Manuscript. University of Pennsylvania.

Blinder, A. (1986) More on the Speed of Adjustment of Inventories. Journal of Money, Credit, and Banking, 18: 355-65.

Bowman, D. and Rogers, J. (1997) An Analysis of Fiscal Policy in the Federal Reserve Board's Global Model. Manuscript. Division of International Finance, Federal Reserve Board.

Brayton, F. and Mauskopf, E. (1985) The Federal Reserve Board MPS Quarterly Econometric Model of the U.S. Economy. Economic Modelling, 2: 170-292.

Brayton, F. and Tinsley, P. (eds.) (1996) A Guide to FRB/US: A Macroeconomic Model of the United States. Finance and Economics Discussion Series, 1996-42. Washington: Federal Reserve Board.

Campbell, J. and Mankiw, G. (1989) Consumption, Income and Interest Rates: Reinterpreting the Time Series Evidence. NBER Macroeconomics Annual. Cambridge: MIT Press. 
Campbell, J. and Shiller, R. (1989) The Dividend-Price Ratio and Expectations of Future Dividends and Discount Factors. Review of Financial Studies. 1: 195-228.

de Leeuw, F. and Gramlich, E. (1968) The Federal Reserve-MIT Econometric Model. Federal Reserve Bulletin, 54: 11-40.

de Leeuw, F. and Gramlich, E. (1969) The Channels of Monetary Policy: A Further Report on the Federal Reserve-MIT Econometric Model. Federal Reserve Bulletin, 55: 472-91.

de Menil, G. and Enzler, J. (1972) Prices and Wages in the FR-MIT-PENN Econometric Model. The Econometrics of Price Determination Conference, ed. O. Eckstein. Washington: Board of Governors of the Federal Reserve System.

Dornbusch, R. (1976) Expectations and Exchange Rate Dynamics. Journal of Political Economy, 84: 1161-76.

Edison, H., Marquez, J., and Tryon, R. (1989) The Structure and Properties of the Federal Reserve Board Multicountry Model. Economic Modelling, 4: 115-315.

Engle, R. and C. Granger (1985) Cointegration and Error Correction: Representation, Estimation, and Testing. Econometrica, 55: 251-76.

Enzler, J. and Pierce, J. (1974).The Effects of External Inflationary Shocks. Brookings Papers on Economic Activity: 13-54.

Fair, R. and Taylor, J. (1983) Solution and Maximum Likelihood Estimation of Dynamic Nonlinear Rational Expectations Models. Econometrica 51: 1169-85.

Fuhrer, J. and Moore, G. (1995) Inflation Persistence. Quarterly Journal of Economics, CX: 127-59. 
Gagnon, J. (1991) A Forward-Looking Multi-Country Model For Policy Analysis: MX3. Economic and Financial Computing, 1: 311-61.

Hansen, L. and Sargent, T. (1980) Linear Rational Expectations Models for Dynamically Interrelated Variables. Rational Expectations and Econometric Practice. eds. R. Lucas and T. Sargent. Minneapolis: University of Minnesota Press.

Kozicki, S., Reifschneider, D., and Tinsley, P. (1996) The Behavior of Long-Term Interest Rates in the FRB/US Model. The Determinants of Long-Term Interest Rates and Exchange Rates and the Role of Expectations. Bank of International Settlements Conference Papers, vol. 2, Basle: Bank of International Settlements.

Kozicki, S. and Tinsley, P. (1996) Moving Endpoints and the Internal Consistency of Agents' Ex Ante Forecasts. Finance and Economics Discussion Series, 1996-47. Washington: Federal Reserve Board.

Levin, A. (1996) A Comparison of Alternative Monetary Policy Rules in the FRB Multi-Country Model. The Determinants of Long-Term Interest Rates and Exchange Rates and the Role of Expectations. Bank of International Settlements Conference Papers, vol. 2, Basle: Bank of International Settlements.

Lucas, R. (1976) Econometric Policy Evaluation: A Critique. The Phillips Curve and Labor Markets, Carnegie-Rochester Conference Series on Public Policy, Amsterdam: North-Holland, 19-46.

Lucas, R., and Sargent, T. (1978) After Keynesian Macroeconomics. After the Phillips Curve: Persistence of High Inflation and High Unemployment, Federal Reserve Bank of Boston.

Masson, P., Symansky, S., Haas, R., and Dooley, M. (1988) MULTIMOD: A MultiRegion Econometric Model. Staff Studies for the World Economic Outlook Washington, 
DC: International Monetary Fund.

Muelbrauer, J. and Lattimore, R. (1995) The Consumption Function: A Theoretical and Empirical Overview. Handbook of Applied Econometrics. eds. H. Pesaran and M. Wickens. Oxford: Blackwell.

Rasche, R. and Shapiro, H. (1968) The F.R.B.-M.I.T. Econometric Model: Its Special Features. American Economic Review, 58: 123-49.

Reifschneider, D., Stockton, D., and Wilcox, D. (1997) Econometric Models and the Monetary Policy Process. Carnegie-Rochester Conference Series on Public Policy, 47, Amsterdam: North-Holland.

Rotemberg, J. (1982) Sticky Prices in the U.S. Journal of Political Economy, 90: 1187211.

Schuh, S. (1996) Evidence on the Link Between Firm-Level and Aggregate Inventory Behavior. Finance and Economics Discussion Series, 1996-46. Washington: Federal Reserve Board.

Shiller, R. (1979) The Volatility of Long-Term Interest Rates and Expectations Models of the Term Structure. Journal of Political Economy, 87: 1190-1219.

Sims, C. (1980) Macroeconomics and Reality. Econometrica, 48: 1-48.

Stevens, G., Berner, R., Clark, P., Hernandez-Cata, E., Howe, H., and Kwack, S. (1984) The U.S. Economy in an Interdependent World: A Multicountry Model. Washington: Board of Governors of the Federal Reserve System.

Taylor, J. (1980) Aggregate Dynamics and Staggered Contracts. Journal of Political Economy, 88: 1-24. 
Taylor, J. (1993a) Discretion Versus Policy Rules in Practice. Carnegie-Rochester Conference Series on Public Policy, 39: Amsterdam: North Holland.

Taylor, J. (1993b) Macroeconomic Policy in a World Economy. New York: Norton.

Tinsley, P. (1993) Fitting Both Data and Theories: Polynomial Adjustment Costs and Error-Correction Decision Rules. Finance and Economics Discussion Series, 93-21. Washington: Federal Reserve Board.

Williams, J. (1997) Simple Rules for Monetary Policy. Manuscript. Division of Research and Statistics, Federal Reserve Board. 